\title{
Hybridized Simple Linear Regression Analysis and Simple Moving Average Statistical Models Web-Based System for Sales Forecast
}

\author{
Isong, Etebong Bassey \& Essien, Ubong Udo \\ Department of Computer Science \\ Akwa Ibom State University \\ Ikot-Akpaden, Akwa .Ibom State, Nigeria. \\ E-mail: etebongisong@aksu.edu.ng
}

\begin{abstract}
The advances in the science of economic forecasting have been made possible by progress in computer technology. Web-based system for sales forecast uses Simple linear Regression analysis (SLR) and Simple Moving Average (SMA) statistical model to carry out sales forecast using data obtained from daily business sales. In Simple Linear Regression analysis, sales is related to one explanatory (independent) variables. These explanatory variables may be marketing decisions for instance price changes, competitive information, economic data or any other variable that can be related to sales. While Simple Moving Average analysis is a procedure in which sales data average is computed by dropping the oldest observation and including the next observation. The result of the analysis is forecasted via the web platform. Hence, the Management can make intelligent business decision based on the result of the forecast.
\end{abstract}

\section{Keywords: Web-based Systems, Sales forecast, Simple Moving Average, Variables and Observation}

CISDI Journal Reference Format

Isong, Etebong Bassey \& Essien, Ubong Udo (2019):Hybridized Simple Linear Regression Analysis and Simple Moving Average Statistical Models Web-Based System for Sales

Forecast.Computing,InformationSystems,DevelopmentInformatics\&AlliedResearchJournal.Vol10No1.Pp 51-72.

Availableonlineatwww.cisdijournal.org

DOI Affix - https://doi.org/10.22624/AIMS/CISDI/V10N1P5

\section{INTRODUCTION}

Forecast is a prediction, projection, or estimate of some future activity, event, or occurrence. A sales forecast is an essential tool for managing a business of any size. This entails a month-by-month forecast of the level of sales the business establishment expects to achieve. Sales forecasting is the process of estimating what the business's sales are going to be in the future. A sales forecast period can be monthly, quarterly, half-annually, or annually. Sale forecasting is an integral part of business management, of which without a solid idea of what the future sales are going to be, the business establishment cannot manage their inventory or their cash flow or plan for growth. The purpose of sales forecasting is to provide information that the Company can use to make intelligent business decisions. Accurately forecasting the sales and building a sales plan can help a business establishment to avoid unforeseen cash flow problems and manage their production, staff and financing needs more effectively (Ward, 2016). According to Jobber and Lancaster (2003), there are different periods when predictions for some results are made. It comprises of short term forecasts, medium term forecasts and long term forecasts. However, there are also majorly two techniques of forecasting such as qualitative or quantitative techniques. Qualitative forecasting techniques are used in the nonpredictable environment and when there is paucity of data. It is also referred to as judgmental of subjective techniques because they rely more upon opinion and less upon mathematics in their formulations. 
While quantitative forecasting techniques are applied when environment is predictable and when there are data from past period about sales. This technique uses mathematics' techniques for forecasting. (Martinovic and Damnjavovic, 2006). A web-based system is an intelligent system that uses a web as a platform or web-based technologies to deliver services in which the user interfaces are web enabled. Web-based system for sales forecast will be implemented using statistical models such as Simple Linear Regression analysis and Simple Moving Average as methods of quantitative techniques to carry out sales forecast on bottle and sachet table water sales on web platform.

\subsection{The Case Study - Arsan Table Water Company}

Arsan Table Water Company is one of the largest producer and distributor of bottle and sachet table water, from their warehouse at Ikot Ekpene Akwa Ibom State, Nigeria. In the South South geo-political zone, Arsan Company serve approximately 5 million people by producing and distributing a unique portfolio of quality brand table water, bringing passion to market place implementation and demonstrating leadership in Corporate Social Responsibility. The table water Company have a rich heritage and an exciting future from the creation of the Company in 2005 to being recognized as one of the industry leaders. The vast territory of Akwa Ibom State, opens up opportunities for the table water Company but also brings challenges in knowing the level of production in other to meet the pressing demand of consumers. As such the company like any other establishment is constantly looking for an accurate way of knowing the future state of it business.

\subsection{Research Problem}

Sales are the driving force of every business. Some business companies find it difficult to carry out financial planning, including cash flow management, production planning to determine the right level of supplies are ordered and the production process is efficient to meet either higher levels or lower levels of production, human resource planning, getting the right number and type of staff in the jobs that are needed. This may mean recruiting more staff, retaining staff or making staff redundant and to reduce taking risk that could affect business performance. However, on the other hand, Sales forecasting can help business decide on the kind of commodity to stock. It also help in the financial planning of a business. It is a self-assessment tool that uses past and current sales statistics to intelligently predict future performance. Therefore, it is pertinent to develop a web-based system for sales forecasting using Simple Linear Regression analysis and Simple Moving Average statistical models to assist the Table water business company to make timely decisions.

\subsection{Research Aim}

The aim of this research work is to develop a Web-based system application capable of capturing sales data from table water and use the data to carry out sale forecast using Simple Linear Regression analysis and Simple Moving Average forecasting models.

\section{RELATED WORKS}

Forecast is a prediction, projection, or estimate of some future activity, event, or occurrence. According to Armstrong (2001), forecast is a prediction or estimate of an actual value in a future time period (for time series) or for another situation (for cross-sectional data). Forecasts are numerical estimates of an event for some future date that can be achieved with a specified of support and are reproducible. (Kajjij, 2009). Forecasting involves making the best possible judgment about some future event. It is the estimating in unknown situations. Forecasting is the process of making statements about events whose actual outcomes have not yet been observed. Armstrong (2001). More so, it is a method or a technique for estimating future aspects of a business or the operation. Forecasts are important for shortterm and long-term decisions. Businesses may use forecast in several areas like technological forecast, economic forecast, demand forecast, etc. (Gahirwal and Vijayalakshmi, 2013; Kotler 2003). 
A sales forecast is a prediction based on past sales performance and an analysis of expected market conditions (Vijayalakshmiet al., 2008). Many management and control decisions are often influenced by the current market situation and on how it is expected to change in the near future. Sales forecasts help investors make decisions about investments in new ventures. They are vital to the efficient operation of the firm and can aid managers on such decisions as the size of a plant to build, the amount of inventory to carry etc., (Brockwell and Davis, 2001, Ward, 2016). An accurate prior estimate of the likely changes in the key factors can go a long way in improving the quality of decision taken. Sales forecasting is a self-assessment tool for a Company or any organization. Timely and accurate sales forecast are crucial in bridging the gap between supply and demand. A good forecasting system helps to decrease inventory holding costs while at the same time reducing the probability of stock-outs and customer wait times. (Jobber and Lancaster, 2003).

According to Martinovic and Damnjanovic (2006), the forecasting process refers to a series of procedures used to forecast. It begins when an objective is determined. For example sales objectives can be (estimation of dollar sales, number of sales people to hire, etc.).Next step is determination of dependent, which refers to what is being forecasting: sales or the number of sales people to hire next year) and independent variables. After this step, forecast procedure and methods for analyzing data should be determined.Data are then gathered and analyzed often assumptions must be made about the forecast. The forecast is made, finalized, and, estimate passes, evaluated (Futrell, 1998; Martinovic and Damnjanovic, 2006)

\subsection{Sales Forecasting Methods}

Business managers or marketers forecast sales by:

(a) Extending past behavior also known as quantitative methods (Objective Approach) and/or

(b) Predicting future behavior also known as qualitative methods (Subjective Approach)

\subsection{Extending Past Behavior or Quantitative methods}

Extending past behavior techniques are applied when past sales data are available. These techniques tend to be more quantitative. They extend past data into the future, and assume that the future will be like the past. These techniques include trend extension, the factor method (using one or more factors such as the Buying Power Index, and the SIC code to forecast the sales of industrial products), time series analysis, the use of leading series, and indices such as the consumer price index, producer price index, and the index of leading economic indicators (McCarthy and Perreault, 1987). Quantitative forecasting methods are based on analysis of historical data and assume that past patterns in data can be used to forecast future data points. Quantitative forecasting methods include statistical, state space models and those based on machine learning techniques such as neural networks genetic algorithms etc. Statistical techniques use classical regression or time-series models such as exponential smoothing and Moving Average. (Gahirwal and Vijayalakshmi, 2013). .According to Hyndman, (2009) quantitative methods can be applied when two conditions are satisfied: numerical information about the past is available and it is reasonable to assume that some aspects of the past patterns will continue into the future. There is a wide range of quantitative forecasting methods, often developed within specific disciplines for specific purposes. Each method has its own properties, accuracies, and costs that must be considered when choosing a specific method. Quantitative methods involves time series analysis and use of market research data. 


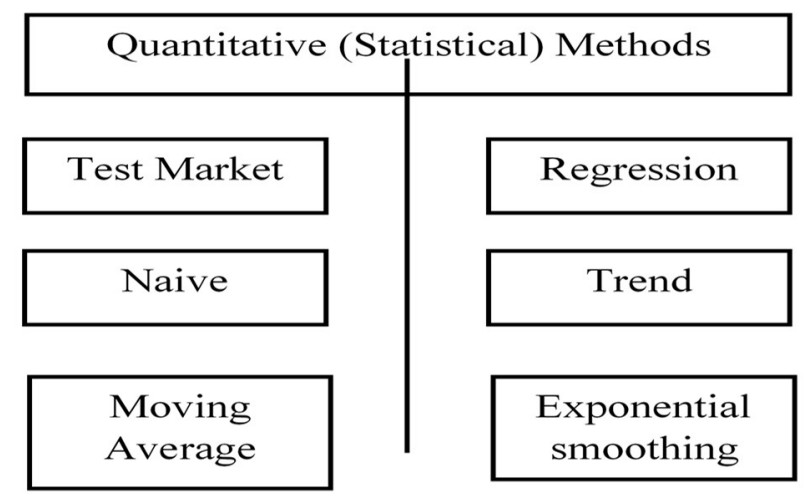

Figure 2.1. Forecasting Diagram of Quantitative methods (Futrell, 1998).

\subsection{Predicting Future Behavior or Qualitative Methods}

Predicting future behavior techniques do not rely on the availability of past data. Instead, they rely on judgment, and are used when there are changing conditions in the market place or changes in the marketing mix used. They are also used to forecast the sale of unstable (fashion) goods and new products. These techniques include the Jury of Executive Opinion, Sales people's estimates, surveys of final buyers, retailers and/or wholesalers, panels of stores and/or final consumers, market tests of existing products, test markets of new products, the substitute method, and needs analysis (Perreault and McCarthy 1996). There is no best method of forecasting in all circumstances. Confidence in the accuracy of sales forecasts is derived by corroborating the results using two or more methods (McCarthy and Perreault 1984).Qualitative forecasting methods employ the judgment of experts in specified field to generate forecasts. They are based on educated guesses or opinions of experts in that area. These methods are used when numerical information about the past is not available and/or it is not reasonable to assume that some aspects of the past patterns will continue into the future Hyndman, (2009). They are also used to adjust quantitative forecasts, taking account of information that was not able to be incorporated into the formal statistical model. These are not purely guesswork but there are well-developed structured approaches to obtaining good judgmental forecasts. Qualitative methods involves Delphi, Brainstorming, Intuition and Expert Opinion methods.

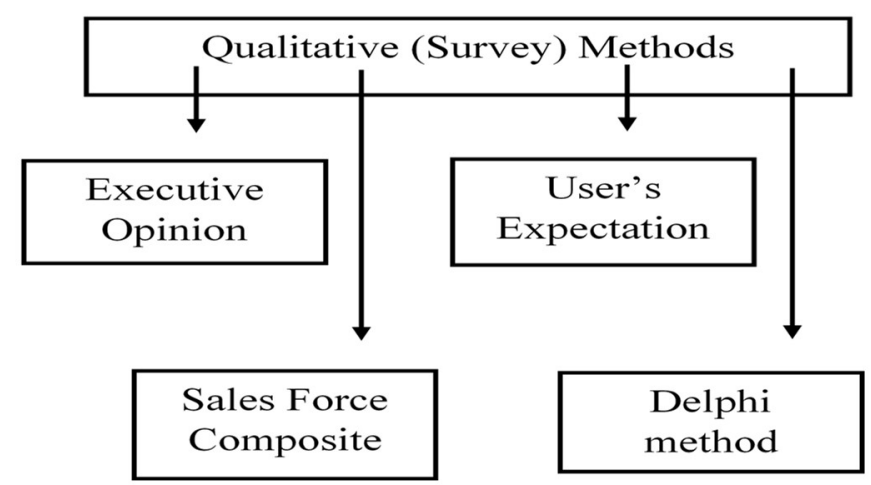

Figure 2.2 Forecasting Diagram of Qualitative methods (Futrell, 1998).

As qualitative methods are non-statistical, they will not be considered further in this research work. 


\section{Sales Forecast with Quantitative Methods (Statistical Models)}

Quantitative methods or statistical models are sometimes termed objective or mathematical techniques as they rely more upon mathematics as less upon judgment in their computation. These methods are now very popular as a result of sophisticated computer packages. However, quantitative methods are estranged into Time-Sseries Models and Associative Models.

\subsection{Time-Series Models}

Time series models look at past patterns of data and attempt to predict the future based upon the underlying patterns contained within those data. It is the examination of historical data that occurs over time, often with the intention of using the data to forecast future data. A time series is a sequence of observations on a variable measured at successive points in time or over successive periods of time. The measurements may be taken every hour, day, week, month, or year, or at any other regular interval. The pattern of the data is an important factor in understanding how the time series has behaved in the past. If such behavior can be expected to continue in the future, then the past pattern behaviour can be used as a guide in selecting an appropriate forecasting method (Mentzer and Kahn,1995). An example is the Moving average model which takes an average of a specified number of past observations to make a forecast. As new observations become available, they are used in the forecast and the oldest observations are dropped.

\subsection{Associative Models}

These models are often called Causal Models, which assume that the variable being forecasted is related to other variables in the environment. They try to project based upon those associations (Mentzer and Kahn, 1995). An example is the Linear Regression analysis which statistically relates sales to one or more explanatory (independent) variables. Explanatory variables may be marketing decisions (price changes, for instance), competitive information, economic data on any other variable that can be related to sales. This research work centers on the use of regression analysis and moving average as statistical models in forecasting sales.

\subsubsection{Sales forecast using Simple Moving Average model}

Simple moving average method is the forecast for next period (period $t+1$ ), which will be equal to the average of a specified number of the most recent observations, with each observation receiving the same emphasis (weight). However, simple moving averages are developed based on an average of weighted observations, which tends to smooth out short-term irregularity in the data series. They are useful if the data series remains fairly steady over time. According to Hyndman, (2009), a moving average is a time series constructed by taking averages of several sequential values of another time series. It is a type of mathematical convolution. Moving averages are also called running means or rolling averages. They are a special case of "filtering", which is a general process that takes one time series and transforms it into another time series. The term "moving average" is used to describe this procedure because each average is computed by dropping the oldest observation and including the next observation. Moving averages are used in two main ways. Hyndman (2009):

i. Two-sided (weighted): This type of moving averages are used to "smooth" a time series in order to estimate or highlight the underlying trend;

ii. $\quad$ One-sided (weighted): This type of moving averages are used as simple forecasting methods for time series. While moving averages are very simple methods, they are often building blocks for more complicated methods of time series smoothing, decomposition and forecasting.

More so, simple moving average can be computed by taking a simple average of the most recent $N$ values, for some integer $N$. This is the equation for predicting the value of $\mathrm{F}$ at time $t+1$ based on data up to time $t$ : 
Moving Average Model:

$\mathrm{F}_{\mathrm{t}}=($ sum of actual values in previous $n$ periods $)$

$\mathrm{n}$

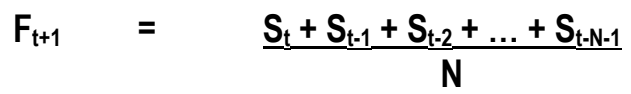

where:

$\mathrm{F}_{t+1} \quad$. $\quad T$ The forecast for Period (time) $t+1$.

$\mathrm{S}_{\mathrm{t}-1} \quad$ - $\quad$ Sales for Period $\mathrm{t}$-1,

$\mathrm{N} \quad$ - $\quad$ Number of Periods in the Moving Average

So the three-period moving average would be:

$F_{3}=\left(S_{t}+S_{t-1}+S_{t-2}\right) / 3$

A four-period moving average would be:

$F_{4}=\left(S_{t}+S_{t-1}+S_{t-2}+S_{t-3}\right) / 4$

A five-period moving average would be:

$F_{5}=\left(S_{t}+S_{t-1}+S_{t-2}+S_{t-3}+S_{t-4}\right) / 5$

and so on, for as many period in the moving average as needed.

For example, simple three-point moving average for a list of five pieces of data relating to the daily sales of product for over five days can be computed as follows:

Table 2.1. Simple Moving Average of data from daily sales of product for five days

\begin{tabular}{|l|l|l|}
\hline Day & Sales $(\mathbf{A})$ & Trend (Simple Moving Average) \\
\hline 1 & 34000 & - \\
\hline 2 & 40000 & First Subset: $(34000+40000+34000) / 3 \quad=36000$ \\
\hline 3 & 34000 & Second Subset: $(40000+34000+46000) / 3=40000$ \\
\hline 4 & 46000 & Third Subset: $(34000+46000+52000) / 3=44000$ \\
\hline 5 & 52000 & \\
\hline
\end{tabular}

Based on the above calculated simple moving average, first point (36000) can be used as the trend point of day 2, with the second point (40000) forming the trend point of day 3 . The trend result shows the trend line for each period of time and forms the basis from which 'Seasonal variations' can be calculated.Seasonal variation is simply the difference between the actual data at a point and the trend at the same point. The seasonal variation is shown in the following table. 
Table 2.2. Simple Moving Average with Seasonal Variation

\begin{tabular}{|l|l|l|l|}
\hline Day & Sales $(\mathbf{A})$ & Trend & Seasonal Variation \\
\hline 1 & 34000 & - & \\
\hline 2 & 40000 & 36000 & +4000 \\
\hline 3 & 34000 & 40000 & -6000 \\
\hline 4 & 46000 & 44000 & +2000 \\
\hline 5 & 52000 & & \\
\hline
\end{tabular}

The above data shows that there is an increase of $\mathbf{A 4 0 0 0}$ in the sales of products when comparing between actual sales made and forecasted (trend) sales on day 2. While there is a decrease of $\$ 6000$ in the sales of products when comparing between actual sales made and forecasted (trend) production on day 3 . With this, the Management can look at the factors causing the increase and decrease in sales and make a timely decision.

\subsubsection{Sales Forecast using Simple Linear Regression analysis model}

Regression analysis includes many techniques for modeling and analyzing several variables, when the focus is on the relationship between a dependent variable and one or more independent variables. Regression analysis is also used to understand which among the independent variables are related to the dependent variable, and to explore the forms of these relationships. Regression analysis can be used to infer causal relationships between the independent and dependent variables. Variables which are used to explain other variables are called explanatory (or independent) variables. A dependent variable is what is measured in the forecast. The dependent variable responds to the independent variable. It is called dependent because it "depends" on the independent variable (Cohen et al., 2003).

\subsubsection{Simple Linear Regression Model}

The simple linear regression model is given by (Mathur, 2013):

Where:

$$
y=\beta_{0}+\beta_{1} x+\varepsilon
$$

$y$ - $\quad$ The dependent or study variable

$x$ - $\quad$ The independent or explanatory variable.

$\beta_{0}$ - The intercept parameter

$\beta_{1}$ - The slope parameter

$\varepsilon$ - The unobservable error parameter

However, the terms $\beta_{0}$ and $\beta_{1}$ are the parameters of the model. These parameters are usually called as regression coefficients. This parameter $\varepsilon$ accounts for the failure of data to lie on the straight line and represents the difference between the true and observed realization of $y$.

$$
\begin{aligned}
& \beta_{0}=\quad Y-\beta_{1} X \\
& \beta_{1}=\frac{\sum X Y-n(Y)(X)}{\sum X^{2}-n(X)^{2}}
\end{aligned}
$$

For instance, simple linear regression model can be used to predict or forecast sales in future days. The data below is used for the analysis: 
Table 2.3. Data from daily sales of product for five days

\begin{tabular}{|l|l|}
\hline Day & Sales $(\mathbf{A})$ \\
\hline 1 & 34000 \\
\hline 2 & 40000 \\
\hline 3 & 34000 \\
\hline 4 & 46000 \\
\hline 5 & 52000 \\
\hline
\end{tabular}

Table 2.4. Simple Linear Regression forecast of data from daily sales of product for five days

\begin{tabular}{|l|l|l|l|}
\hline Day & Day * Day & Sales (\#) & Day ${ }^{*}$ Sales \\
\hline 1 & 1 & 34000 & 34000 \\
\hline 2 & 4 & 40000 & 80000 \\
\hline 3 & 9 & 34000 & 102000 \\
\hline 4 & 16 & 46000 & 184000 \\
\hline & 25 & 52000 & 260000 \\
\hline 3 & 55 & 41200 & 660000 \\
Average & Sum & Average & Sum
\end{tabular}

Days $=X$, while Sales $=Y$

$\beta_{1}=\frac{\sum X Y-n(Y)(X)}{\sum X^{2}-n(X)^{2}}=\frac{660000-5(41200)(3)}{55-5(9)}=\frac{42000}{10}=4200$

$\beta_{0}=\quad Y-\beta_{1} X=41200-(4200)(3)=41200-12600=28600$

Thus, the resulting simple linear regression model is:

$y=\mathbf{2 8 6 0 0}+\mathbf{4 2 0 0 x}$ and sales forecast for day 6 will be: Sales for days $6=28600+4200(6)=\mathbf{N} 53800$

\subsubsection{Increasing the Forecast Accuracy of Sales Forecasting models}

Enhancing forecast accuracy has to do with the measures used in evaluating the forecast errors from a particular model in order to improve the accuracy. According to Gahirwal and Vijayalakshmi, (2013), the forecast error is the difference between the actual value and the forecast value for the corresponding period $(\mathrm{t})$.

\section{Forecast Error $(E t)=$ Actual value $(Y t)-$ Forecasted value $(F t)$}

Forecast accuracy is the optimist's term for forecast errors. It is simply the inverse of the forecast error as a percentage, expressed as follows:

\section{Forecast Accuracy $=(1-$ Forecast Error $) * 100$}

Error measure has an important role in calibrating a refining forecasting model / method. As the main aim in forecasting is to enhance the accuracy of the forecasts, error measures are very important from a forecaster's point of view. There are varieties of error measures that are used in enhancing forecast accuracy. Some of them are listed below: 
- Mean Absolute Deviation (MAD)

$M A D=((\Sigma \mid$ Actual - Forecast $\mid) / n)=((\Sigma \mid$ Error $\mid) / n)$

- Mean Squared Error (MSE)

$M S E=\left(\Sigma(\text { Actual }- \text { Forecast })^{2} / n\right)=\left(\Sigma(\text { Error })^{2} / n\right)$

- Mean Absolute Percent Error (MAPE)

MAPE $=(((\Sigma \mid$ Actual - Forecast $\mid /$ Actual $) * 100) / n)$

In order to enhance forecast accuracy, two or more forecasting models can be employed for prediction, error measure should also be used to evaluate the forecast error rate and the forecasting models' error rate compared so that the forecasting model with lower error measure can be used as the better forecasting model.

\subsubsection{Statistical Models in Sales Forecast}

Forecasting, in general, is a difficult task. As is well known, sales data present strong seasonal variations and its forecasts remains an important problem for forecasters. There are different forecasting models, such as traditional (exponential smoothing, Moving Average (MA), Auto Regressive and Integrated Moving Average (ARIMA) etc.,) and non-traditional methods are employed for solving the problems of sales forecasting. Thomassey et al. (2007) use item classification to examine the accuracy of sales forecasting for new items. They found that a larger number of item families and pertinent classification criteria are required in the respective forecasting procedure in order to achieve an improved forecasting precision. They conclude that product family and aggregated forecasting are more accurate than the individual item's forecasting.

Mostard, Teunter, and de Koster (2011) introduce in their work a new approach which focused on pre-order demand information and apply three methods to advance demand forecasting: preview division, equal division and top-flop division. Yelland and Dong, (2013), examines the applicability of a Bayesian forecasting model for fashion demand forecasting. It was found that the proposed hierarchical Bayesian approach yields superior quantitative results compared to many other methods.

Teucke, Ait-Alla, El-Berishy, Beheshti-Kashi, and Lütjen (2014) focused on pre-orders of seasonal clothing items and suggest a two-step prediction model which is able to estimate the additional post-orders before the actual production is started. Ait-alla et al. (2014) suggest a mathematical model for robust production planning for apparel suppliers. The focus was to support the decision-making on the distribution of articles on different production plants. More so, most of these models are linear and are not able to deal with the asymmetric behaviour in most real-world sales data. These statistical techniques in their original forms face challenges in producing accurate forecast results, due to factors such as irregular patterns and high variability of sales data. 


\section{SYSTEM ANALYSIS}

System analysis is the all-inclusive study of an existing system to ascertain the areas of its functional limitation. It is a concept used in achieving an understanding of the existing system and what is required of it. System analysis identifies the questions and issues to be addressed, identity it strength and weakness, gathering and understanding requirements and characteristics of an existing system. However, system analysis has its objectives, which is to find the mode of operation of the existing system and its drawback so that the proposed system can be designed and fully implemented with the purpose of solving the problems connected with the existing system.

\subsection{Analysis of The Existing System}

In the existing system, there are various statistical models employed in forecasting sales:

Mostard, Teunter, and de Koster (2011) introduce in their work a new approach which focused on pre-order demand information and apply three methods to advance demand forecasting: preview division, equal division and top-flop division. Teucke, Ait-Alla, El-Berishy, Beheshti-Kashi, and Lütjen (2014) focused on pre-orders of seasonal clothing items and suggest a two-step prediction model which is able to estimate the additional post-orders before the actual production is started.Ait-allaet al. (2014) suggest a mathematical model for robust production planning for apparel suppliers. The focus was to support the decision-making on the distribution of articles on different production plants. More so, most of these models are linear and are not able to deal with the asymmetric behaviour in most real-world sales data. These statistical techniques in their original forms face challenges in producing accurate forecast results, due to factors such as irregular patternsand high variability of sales data. In order to enhance forecast accuracy, two or more forecasting models (that is linear and non-linear) can be employed for predictions and their result compared so that the one with most accurate result is accepted.

\subsection{The Existing System Architecture}

The existing system processes of sales forecast is illustrated below:

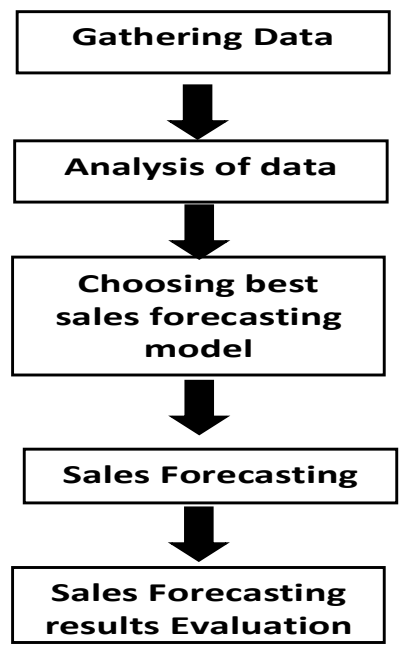

Figure 3.1. Process architecture for sales forecasting 


\subsubsection{Problems with the Existing System}

After analyzing the existing system of forecast of future sales, several problems were associated, which includes:

a. Difficulty in having accurate sales forecast result due to irregular patterns of sales data.

b. High variability of sales data is also a challenge to performing sales forecast on daily and monthly bases.

c. Inability to capture and documenting daily sales data from bottled and sachet table water for forecast.

\subsection{Analysis of the Proposed System}

The proposed system is a web-based intelligent system application capable of capturing sales data from bottled and sachet table water and use the data to carry out sale forecast using Simple Linear Regression analysis and Simple Moving Average forecasting models to succor the Management Table Water business to make timely decisions as well as generating report regarding customer orders, bottle and sachet water sales.

The proposed system will employ some web technologies such as Hypertext Markup Language (HTML), Cascading Style Sheet 3 (CSS 3), Javascript, PHP: Hypertext Preprocess and Firebase database.

The proposed system will have the following modules and submodules:

i. $\quad$ Homepage: This module will display the information about the company and researcher.

ii. $\quad$ Customer Order: This module will help the customers to place order at anytime and anywhere.

iii. Admin Login: This module is a security module which allows access to only authorized persons. With this module access to the following submodules are achieved:

a. Sales: This submodule allows the sales person to register sales information made from bottle and sachet table water, to database.

b. Bottle water forecast: This submodule captures bottle water sales data from past and current to perform analysis using Simple Moving Average model and Simple Linear Regression Model and predict the future sales.

c. Sachet water forecast: This submodule captures sachet water sales data from past and current to perform analysis using Simple Moving Average model and Simple Linear Regression Model and predict the future sales.

d. Order report: This sub module allows order information report to be displayed, viewed and printed.

e. Bottle sales report: With this sub module, bottle table water sales' information report can be displayed, viewed and printed.

f. Sachet sales report: With this sub module, sachet table water sales' information report can be displayed, viewed and printed.

\subsubsection{Rational Unified Process}

Rational Unified Process (RUP) is a software engineering process aimed at guiding software development organizations in their endeavours. It is an object oriented and web-based program development methodology. It provides guidelines i.e. templates for all aspects and stages of program development. This methodology involves building and designing a system in a succession. Each succession involves Planning and Evaluation, Requirement, Analysis and Design, and Implementation and Testing. 


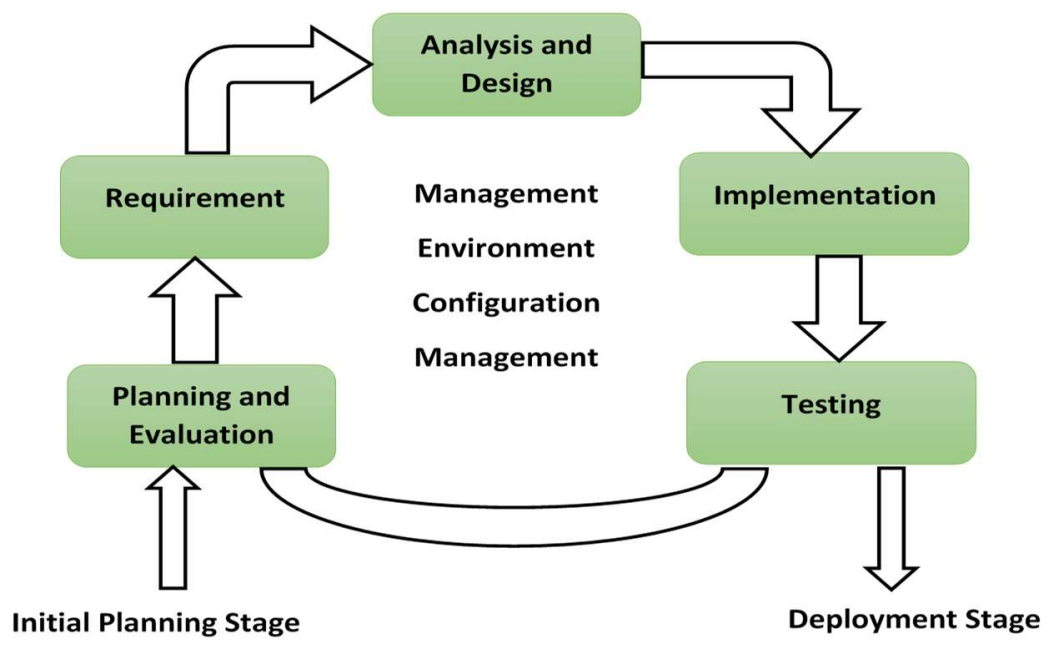

Figure 3.2. Rational Unified Process flow diagram

\subsubsection{New System Architecture}

System Architecture gives a high level view of the new system with the main components of the system and the services they provide and how they communicate. The system is implemented using a three-tier architecture that comprises of user interface, process management and Database Management System (DBMS) as illustrated below.

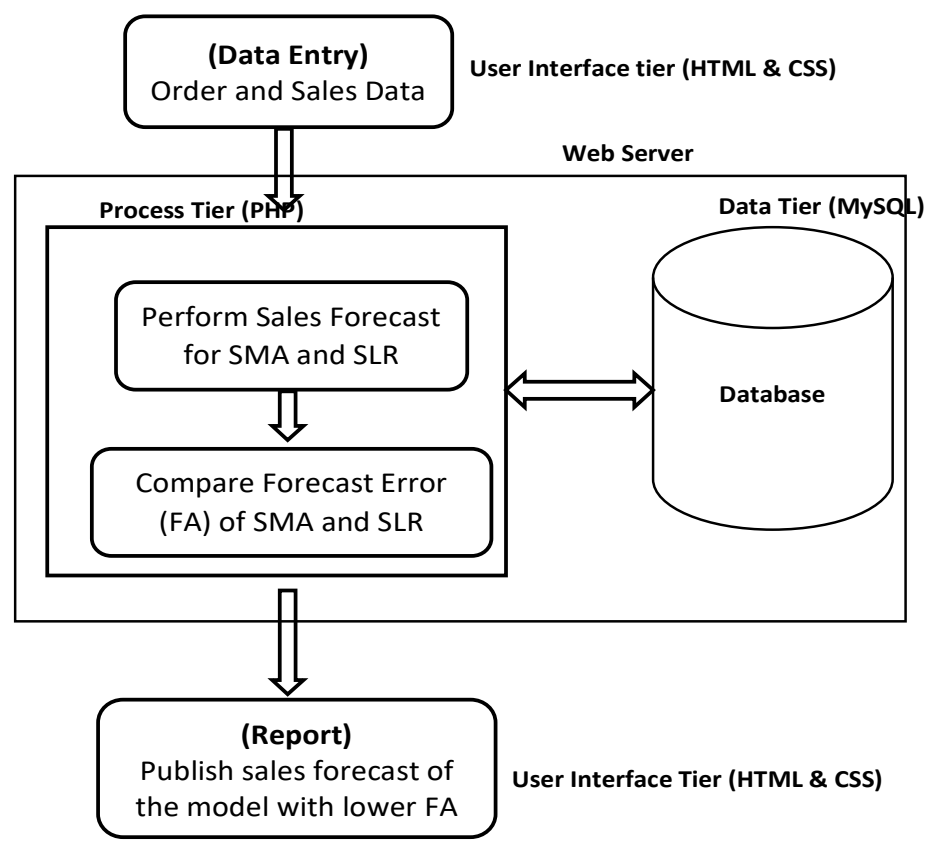

Figure 3.3. Proposed System Architecture 


\subsection{Components Description}

The description of various components of the proposed system architecture are detailed below:

i. User Interface tier: This tier is the communication interface for data entry where order transaction and sales data are entered and saved to database. It also serves as a medium for displaying information report of the sales forecast and product sales. Hypertext Markup Language (HTML) and Cascading Style Sheet (CSS) are used for the developing of this interface.

ii. Process Tier: This tier is handled by the web server. It is the core component of this system. It saves and retrieves the order transaction and sales data as well as information report to and from the database. It is also uses the sales data retrieved from the database to perform sales forecast with Simple Moving Average (SMA) and Simple Linear Regression (SLR) models and compare the forecast error results from the two models, in order to publish the sales forecast result of the model with lower Forecast Error. PHP: Hypertext Preprocessor (PHP) is used for the developing of this interface.

iii. Data Tier: This is an important component that stores order transaction and daily product sales data. It is MySQL, a relational database hosted by the web server.

\section{SYSTEM DESIGN AND IMPLEMENTATION}

The new system is comprises of some input forms, such as:

\section{i. Order form:}

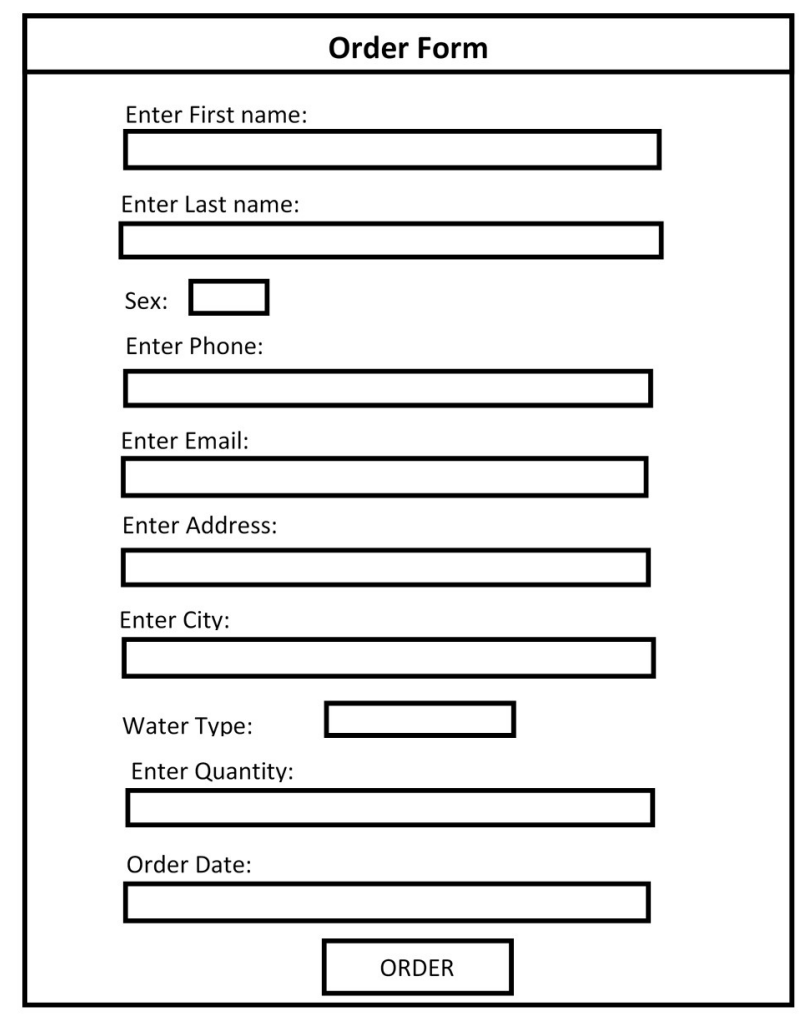

Figure 4.1: Input Design (Order Form) 


\section{ii. Staff Login form}

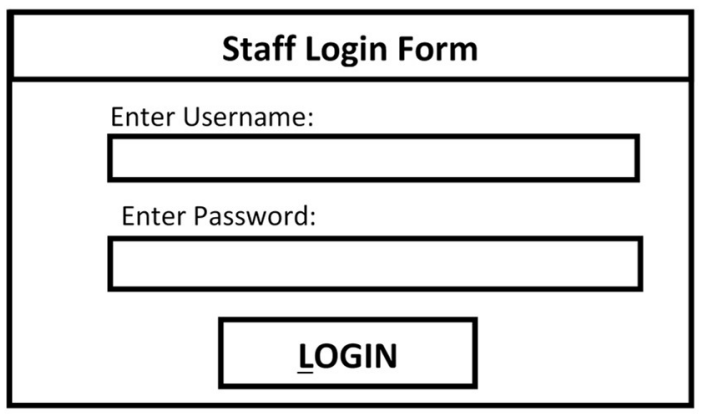

Figure 4.2: Input Design (Login form)

\section{iii. Sales form}

\section{Sales Form}

Water Type:

Quantity Issued:

Quantity Sold:

Enter Price by bag:

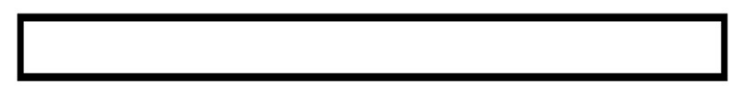

Enter Bus Plate Number:

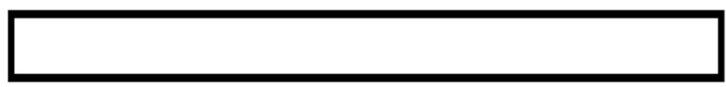

Enter Sales Agent:

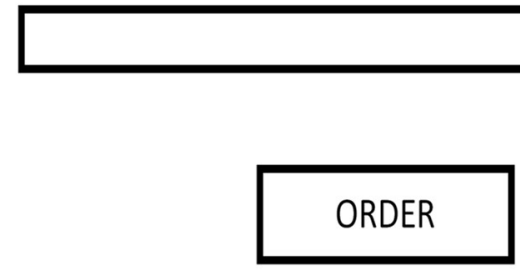

Figure 4.3: Input Design (Sales Form) 


\subsection{Database Design}

The database management used in this research work is MySQL databases. The required entity (table) of the database is structured as follows:

\section{Table 4.1: Login}

\begin{tabular}{|l|l|l|}
\hline Field & Data type & Field size \\
\hline Id & Auto Inc (PK) & 10 \\
\hline Uname & Text & 30 \\
\hline Pword & Text & 10 \\
\hline
\end{tabular}

Table 4.2: order

\begin{tabular}{|l|l|l|}
\hline Field & Data type & Field size \\
\hline Id & Auto Inc. & 10 \\
\hline Tid & Text & 20 \\
\hline Firstname & Text & 15 \\
\hline Lastname & Text & 15 \\
\hline Gender & Text & 6 \\
\hline Phone & Text & 11 \\
\hline Email & Text & 15 \\
\hline Address & Text & 30 \\
\hline City & Text & 15 \\
\hline Water_type & Text & 10 \\
\hline Quantity & Number & 10 \\
\hline Date & Date & \\
\hline
\end{tabular}

Table 4.3: Sales

\begin{tabular}{|l|l|l|}
\hline Field & Data type & Field size \\
\hline Id & Auto Inc. & 10 \\
\hline Tid & Text & 20 \\
\hline Trans_date & Date & \\
\hline Water_type & Text & 10 \\
\hline Quantity_issued & Number & 15 \\
\hline Quantity_sold & Number & 15 \\
\hline Quantity_returned & Number & 15 \\
\hline Price & Number & 15 \\
\hline Bus_plate & Text & 15 \\
\hline Sales_agent & Text & 30 \\
\hline Total_amount & Number & 10 \\
\hline
\end{tabular}




\subsection{Output Design}

The output design helps deliver meaningful timely and purposeful information in a specified format. Information stored in the database which could be retrieved at any time for viewing and printing. The output design illustrated as shown below:

Table 4.4: Output Design (Order Report)

\begin{tabular}{|c|c|c|c|c|c|c|c|c|c|c|}
\hline Tid & $\begin{array}{l}\text { First } \\
\text { Name }\end{array}$ & $\begin{array}{l}\text { Last } \\
\text { Name }\end{array}$ & Gender & Phone & Email & Address & City & $\begin{array}{l}\text { Water } \\
\text { type }\end{array}$ & Quantity & date \\
\hline Ord-238923 & James & Friday & Male & 08123839823 & Jamfry12@gmail.com & $\begin{array}{l}22 \text { abak } \\
\text { rod. }\end{array}$ & Uyo & Sachet & 100 & $2018-08-12$ \\
\hline
\end{tabular}

\section{Use Case Diagram}

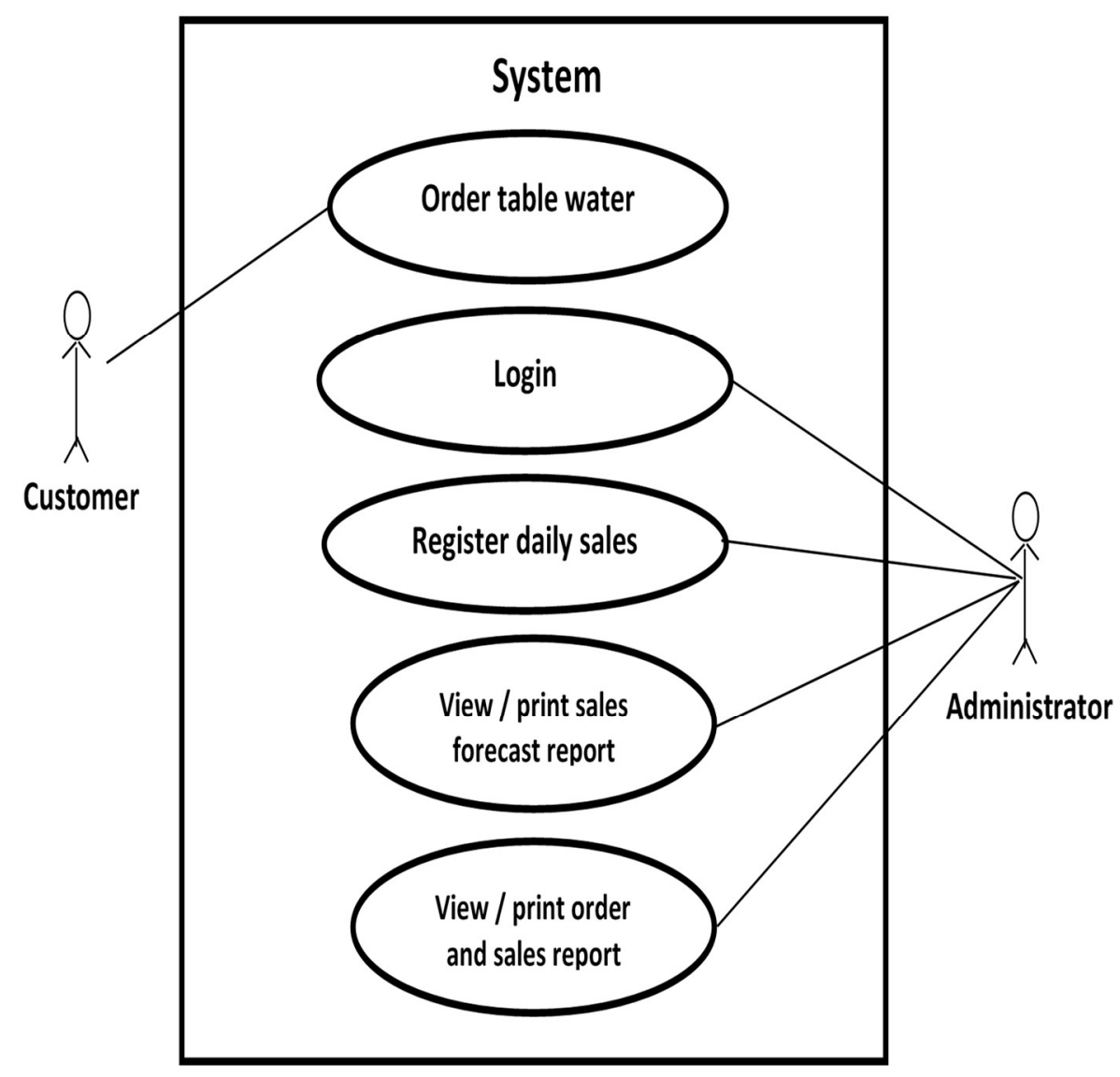

Figure 4.4. Use Case Diagram 


\subsection{System Implementation}

This is a project Sample implementation input and output snapshots:

\section{System Implementation Input Snapshot}

Order form: This is a web application module that enables capturing of customers' table water order and stores the data into the database.

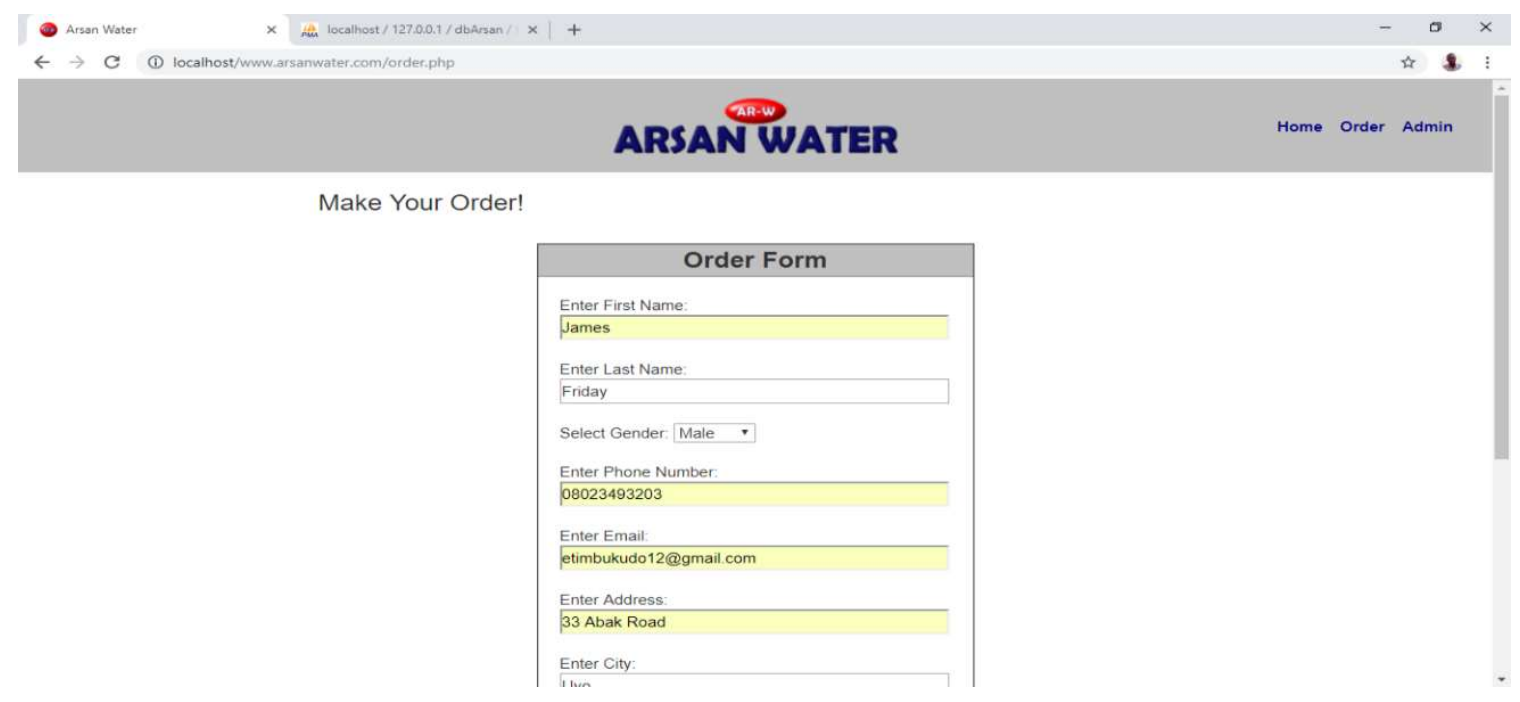

Login form: This is a web application module that allows the staff to have access granted to the main page suppling valid username and password.
- Arsan Wate
$\times$ De locahost/12700.1/dbarsan// $\times \mid+$
$-0$
$\leftarrow \rightarrow$ C (1) localhost/www.arsanwater.com/admin.php
or is $\theta$ :

\section{ARSAN WATER}

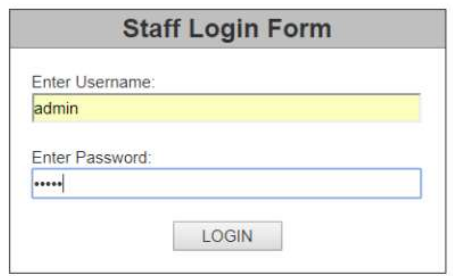


Sales Form: This is a web application module that enables the staff after login is successful to enter sales details which are stored into the database.

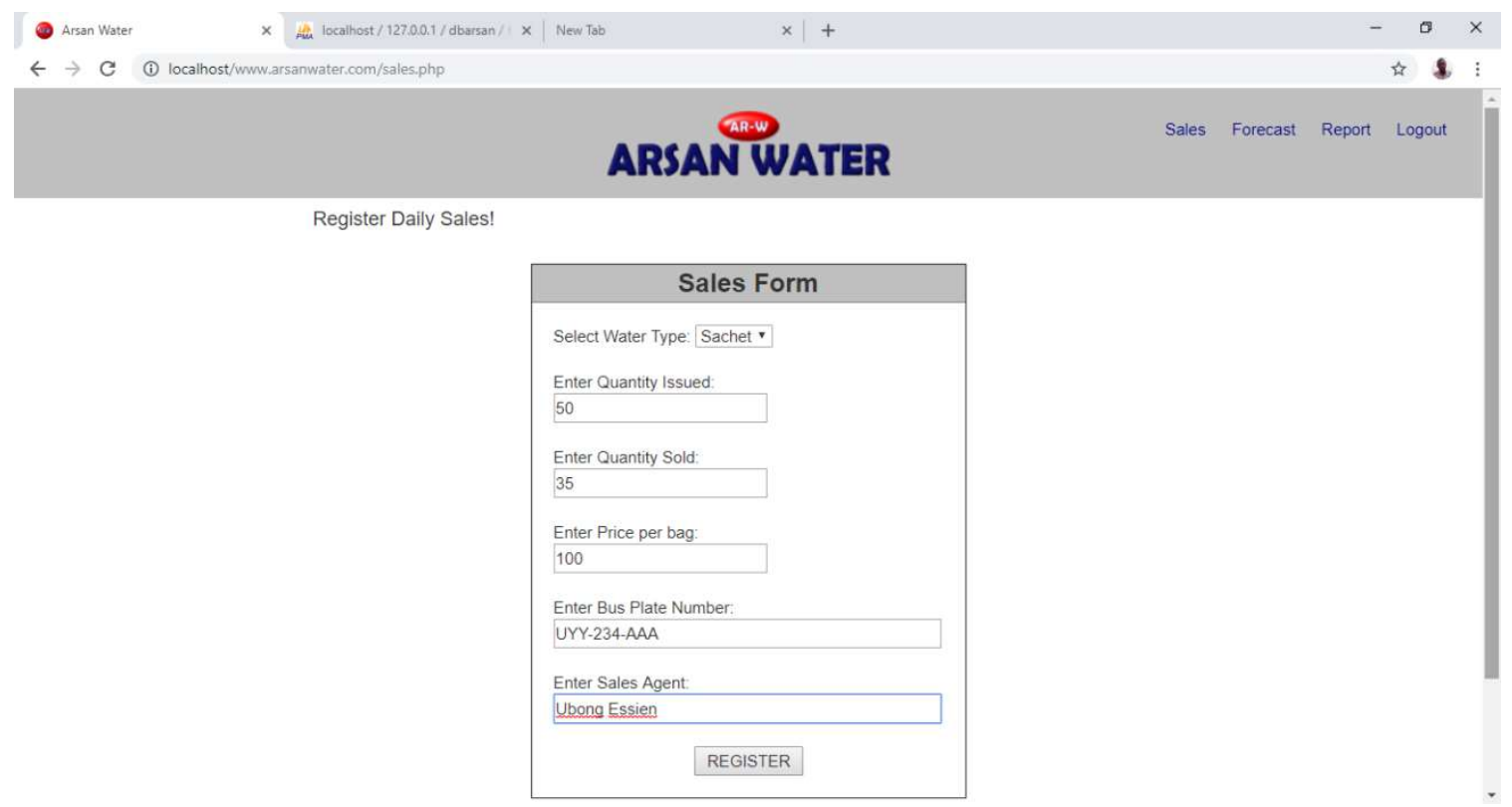

\section{System Implementation Output Snapshot}

Sales Forecast: This is a web application module that retrieves the sales information, compute sales forecast based on two models such Simple Moving Average and Simple Linear Regression and display the prediction of the model with lower forecast error, which can be viewed or printed.

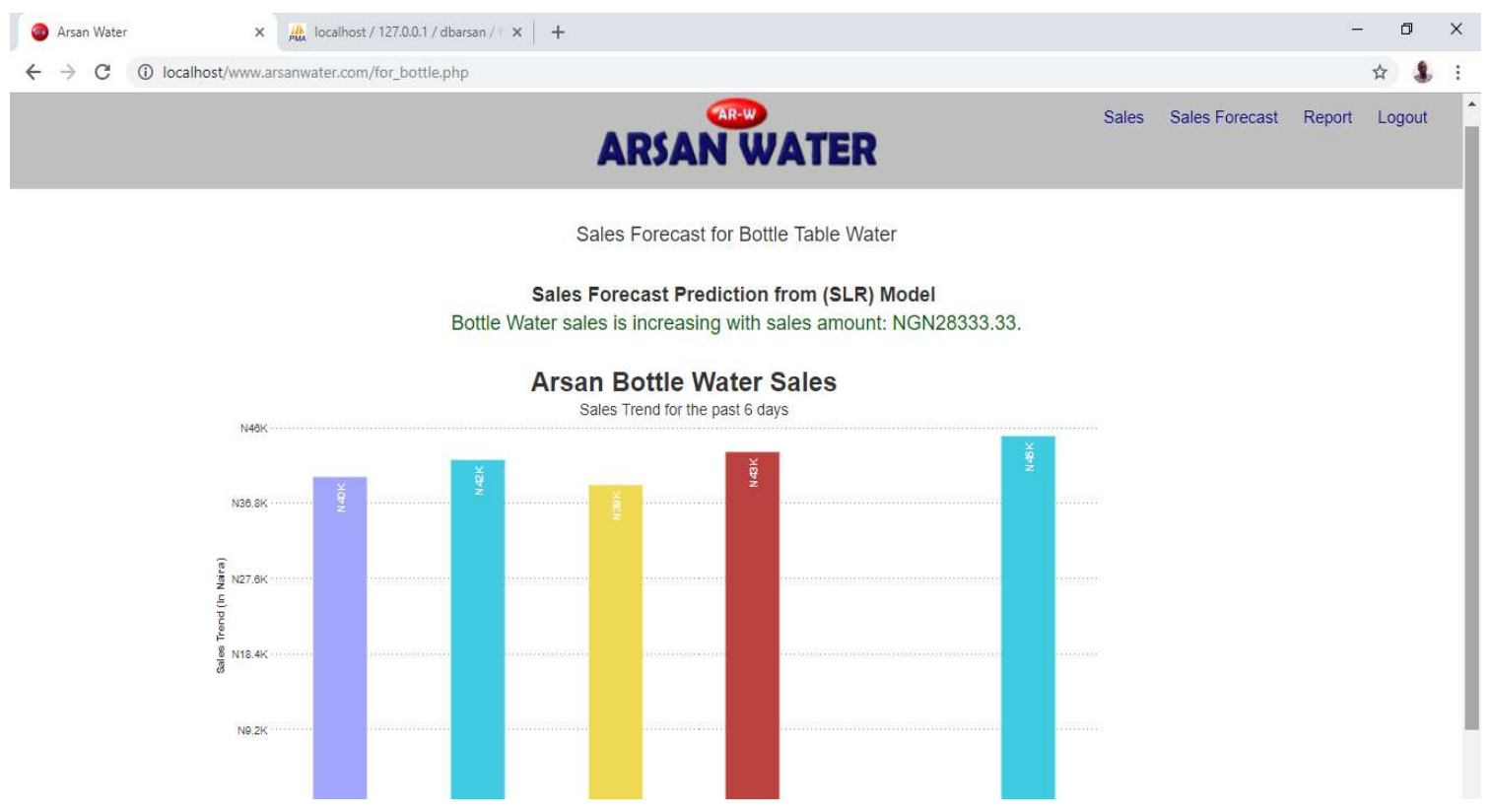


Report: This is a web application module that enables orders, bottle water and sachet water sales information to be retrieved from the database, viewed or printed.
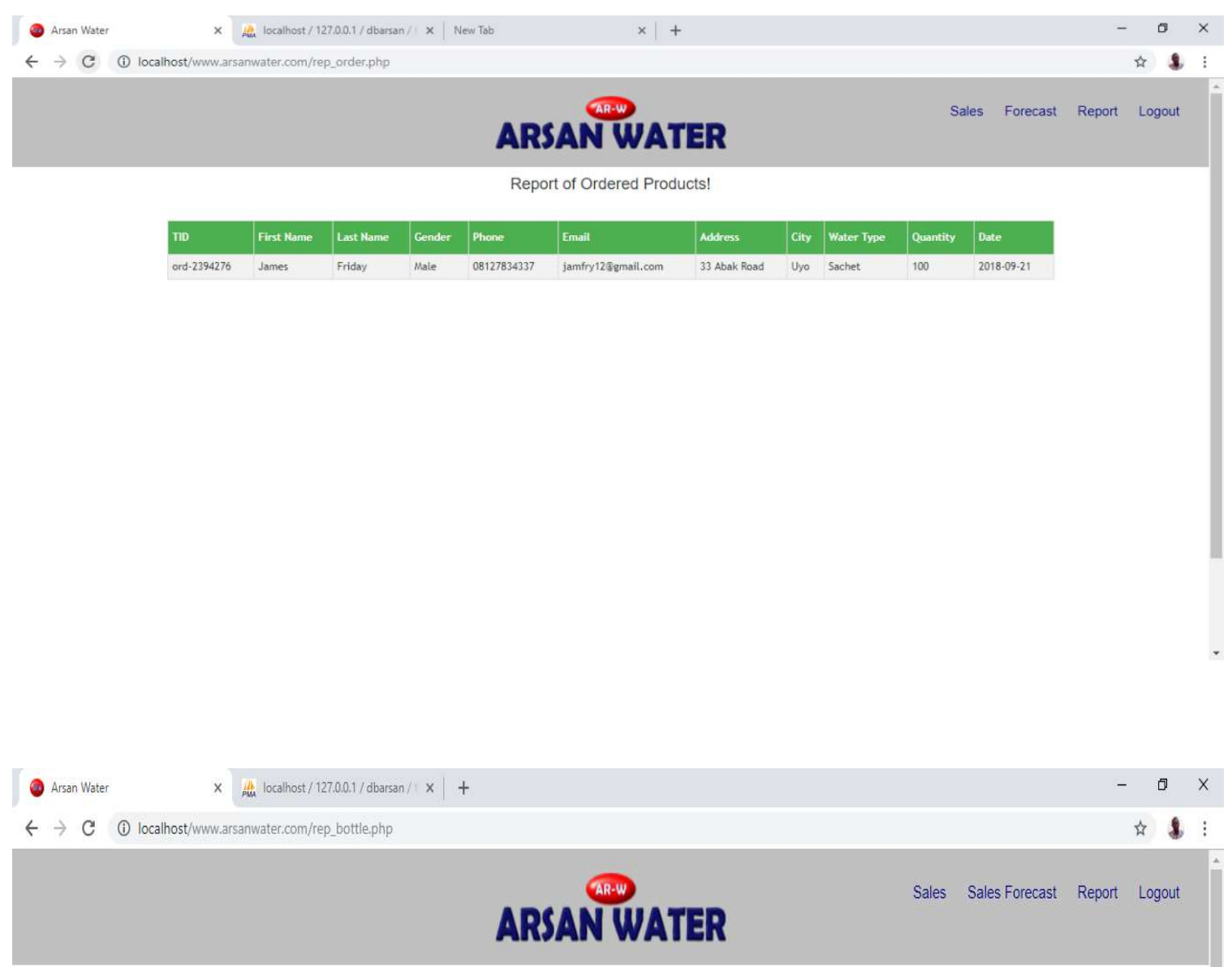

Report of Bottle Table Water Sales!

\begin{tabular}{|l|l|l|l|l|l|l|l|l|l|}
\hline TID & Sales Date & Water Type & Quantity ksued & Quantity Sold & Quantity Returned & Price & Bus Plate & Sales Agent/ths & Total Amount \\
\hline sal-3584631 & $2018-09 \cdot 18$ & Bottle & 50 & 40 & 10 & 1000 & UYY-234-AAA & Ubong Essien & 40000 \\
\hline sal-7911264 & $2018-09-19$ & Bottle & 50 & 40 & 10 & 1000 & UYY-234-AAA & Ubong Essien & 40000 \\
\hline sal-6686092 & $2018-09-20$ & Bottle & 45 & 42 & 3 & 1000 & UYY-234-AAA & Ubong Essien & 42000 \\
\hline sal-8493170 & $2018-09-21$ & Bottle & 50 & 39 & 11 & 1000 & UYY-234-AAA & Ubong Essien & 39000 \\
\hline sal-618898 & $2018-09-22$ & Bottle & 50 & 43 & 7 & 1000 & UYY-234-AAA & Ubong Essien & 43000 \\
\hline sal-63512246 & $2018-09-24$ & Bottle & 50 & 45 & 5 & 1000 & UYY-234-AAA & Ubong Essien & 45000 \\
\hline
\end{tabular}




\subsection{Evaluation of Results}

After developing, testing and evaluating the new system, some successes were recorded due to the fact that webbased intelligent system application was capable of capturing customers' orders and sales data from bottled and sachet table water as well as using the data to carryout sale forecast using Simple Linear Regression analysis and Simple Moving Average forecasting models. The forecast error was computed for both models, while the prediction from the model with higher forecast accuracy was published. Apart from the application being able to forecast sales, the system was capable of capturing and documenting daily sales data from bottled and sachet table water and helped the Management to keep track of information regarding customers and orders as well as generating report and securely protecting customers' orders' and sales information from unauthorized persons.

\subsection{Discussion of Results}

The result of this system has helped the Management in capturing and documenting daily sales data from bottled and sachet table water, making timely decision based on the result of sales forecast analyses performed on daily sales data while also ensuring that the Management keep track of information regarding customers and orders as well as generating report.

\section{CONCLUSION}

At the end of this research work, a Web-based intelligent system application capable of capturing sales data from table water and use the data to carry out sale forecast using Simple Linear Regression analysis and Simple Moving Average forecasting models was developed. This research work has provided the Management with a web-based system capable of capturing and documenting daily sales data. The system uses past and current sales data to perform sales forecast analyses based on daily and monthly records. It also keeps track of information regarding customers and orders as well as generate report and also securely protect customers' orders' and sales information from unauthorized persons.

\subsection{Suggestions for Future Research}

This web-based system for sales forecast is very flexible and open to more improvements. These improvements are expected on this work with the view to deploying other related models to make it more efficient for forecasting in a competitive business environment. 


\section{REFERENCES}

1. Ait-alla, A., Teucke, M., Lütjen, M., Beheshti-Kashi, S., \&Karimi, H. R. (2014). Robust production planning in fashion apparel industry under demand uncertainty via conditional value at risk. Mathematical Problems in Engineering, 2014, 10 pp.

2. Armstrong J. Scott, (2001). "Combining Forecasts. Principles of Forecasting:" A Handbook for Researchers and Practitioners, Norwell, MA: Lower Academic Publishers.

3. Brockwell, P.J., and Davis, R.A., (2001). "Introduction to Time Series and Forecasting", second edition Springer-Verlag, New York.

4. Cohen, J., Cohen, P., West, S. G., \& Aiken, L. S. (2003). Applied multiple regression/correlation analysis for the behavioral sciences, 3rd Ed. Mahwah, NJ: Lawrence Erlbaum Associates.

5. Essays, UK. (November 2013). Web Based Information Systems. Retrieved from https://www.ukessays.com/essays/information-systems/web-based-information-systems.php?vref=1

6. Futrell, C. M. (1998). Sales Management -Teamwork, Leadership and Technology, Orlando, The Dryden Press, p.167.

7. Gahirwal, M. and Vijayalakshmi, M. (2013). Inter time series sales forecasting, Information Technology, Vivekanand Education, Society's Institute of Technology, Chembur, India.

8. Hyndman, R. J. (2009). Moving Averages. An online material retrieved from https://robjhyndman.com/papers/movingaverage.pdf

9. Hyndman, R.J. (2009). "Forecasting overview". An Internet material retrieved from https://robjhyndman.com/papers/forecastingoverview.pdf

10. Jobber, D. and Lancaster, G. (2003). Selling and Sales Management, London, Pearson Education, p. 412-3.

11. Kajiji, N. (2009). Advanced Business Forecasting. An online material retrieved from www.ninakajiii.net.

12. Kotler, P. (2003), Marketing Management, 11th ed. Upper Saddle River, NJ: Prentice-Hall.

13. Kuzhda, T. (2012). Retail sales forecasting with application the multiple regression. Socio-Economic Problems and the State [online]. Vol.1 (6). p. 91-101. Retrieved from http://sepd.tntu.edu.ua/images/stories/pdf/2012/12ktibrm.pdf.

14. Martinovic, J. and Damnjanovic, V. (2006). The Sales Forecasting Techniques. International Scientific Days, Faculty of Economic and Management SAU in Nitra "Competitiveness in the EU - Challenge for the V4 countries" Nitra, pp. 526-527.

15. Mathur (2013).Simple Linear Regression Analysis. Regression Analysis. An online material retrieved from http://home.iitk.ac.in/ shalab/regression/Chapter2-Regression-SimpleLinearRegressionAnalysis.pdf

16. McCarthy, E. J. \&Perreault, Jr., W. D. (1984), Basic Marketing, 8th ed. Homewood, IL: Irwin.

17. McCarthy, E. J. \&Perreault, Jr., W. D. (1987), Basic Marketing, 9th ed. Homewood, IL: Irwin.

18. Mentzer, J. and Kahn, K. (1995). Forecasting Techniques Familiarity, Satisfaction, Usage and Application, Journal of Forecasting, Vol 14., John Wiley\&Sons,., p. 465-476.

19. Mostard, J., Teunter, R., \& de Koster, R. (2011). Forecasting demand for single-period products: A case study in the apparel industry. European Journal of Operational Research, 211(1), 139-147. Retrieved from http://linkinghub.elsevier.com/retrieve/pii/S0377221710007484

20. Perreault, Jr., W. D., Jr. \& McCarthy, E. J. (1996), Basic Marketing: A Global-Managerial Approach, Chicago, IL: Irwin.

21. Small Scale Business Africa (SSEBA) (2018). Bottle/Sachet Water Production. An online material retrieved from http://www.smallscalebusinessafrica.com/water.php

22. Springer, J. (2016).Intelligent System. University of Nevada, Reno. Retrieved from: https://www.unr.edu/cse/prospective-students/what-are-intelligent-systems 
23. Teucke, M., Ait-Alla, A., El-Berishy, N., Beheshti-Kashi, S., \&Lütjen, M. (2014). A sales forecasting model for new released and nonlinear sales trend products. Expert Systems with Applications, 37(11), 7387-7393. Retrieved from http://linkinghub.elsevier.com/retrieve/pii/S0957417410003039

24. Thomassey, S., Happiette, M. and Castelain, J. M., (2007). "Mean-term textile sales forecasting using families and items classification," Studies in Informatics and Control, vol. 12, no. 1, pp. 41-52.

25. Vijayalakshmi M., Menezes B., VenuGopal (2008). "Forecasting using consistent experts", International Conference on Management of Data COMAD.

26. Ward, S. (2016). Understanding Sales Forecasting. Accessed from: https://www.thebalance.com/salesforecasting-2948317.

27. Yelland, P. M. and Dong, X. J., (2013). "Forecasting demand for fashion goods: a hierarchical Bayesian approach," in Handbook on Intelligent Fashion Forecasting Systems, 2013. 